\title{
Morphology, Food and Feeding Habit of Goby Fish, Parachaeturichthys ocellatus from the Creeks of Mumbai
}

\author{
Bindu Panicker* \\ Maharashtra College of Arts, Science and Commerce, Mumbai, India \\ *Corresponding author: bindu238@gmail.com
}

\begin{abstract}
Goby fish Parachaeturichthys ocellatus, native to the creeks of Mumbai coast forms a major part of creek fishery for the fishing community inhabiting areas near the creeks. The food and feeding habits of the fish were studied by collecting fish samples every month in from June 2010 to September 2011 from the creeks of Mumbai. The length of the fishes studied ranged between $66 \mathrm{~mm}$ to $185 \mathrm{~mm}$. The body morphology of fish revealed it to be carnivorous benthic and predatory fish. The gut contents of the fish showed the presence of crustaceans as basic food, mollusc and pisces formed the secondary food while detritus formed obligatory food and planktons and other miscellaneous food (larvae of insects, worms, rotiferons, dinoflegellates foraminiferons etc.) were incidental food. An analysis of seasonal variation in food preference and feeding intensity reveal that the male and female P.ocellatus had the same preference throughout the seasons but was different for the juveniles. In P.ocellatus cannibalism was observed, but its occurrence was not regular in the general diet. The relative gut length was 0.68 in male, 0.70 in female and 0.79 in juvenile. The empty guts of $P$.ocellatus seem to indicate predatory mode of feeding. P.ocellatus occupy the position of secondary and tertiary consumers in the food chain determined by the size and type of the food consumed by the fish.
\end{abstract}

Keywords: Feeding intensity, Morphology, Relative gut length gastrosomatic index.

\section{Introduction}

The feeding behaviour in a fish is a species characteristic formed during its evolutionary history (Nikolsky, 1963). The general nature of a fish's feeding habits can be inferred from the knowledge of its functional morphology (Weatherly, 1972). Food habits of gobies are very diverse consisting of crabs, shrimps, small crustaceans like copepods, amphipods and ostracods, molluscs and fishes (Jonna, 2004). Gobies of all sizes eat small molluscs and crustaceans, small and medium sized gobies eat polychaetes but only larger individuals eat other fish (Skazkinia and Kostyuchenko,1968 and Kovtun et al., 1974).

Parachaeturichthys ocellatus is native to Western Indian Ocean and Western Central Pacific Ocean at $30^{\circ} \mathrm{E}-80^{\circ} \mathrm{E}$ and $45^{\circ} \mathrm{S}-30^{\circ} \mathrm{N}$. It was identified by Day (1873) from the creks of Mumbai. Mutsaddi and Bal (1973) reported that P. ocellatus occurs in the muddy creeks of Colaba, Worli, Mahim, Danda, Madh, Mahul, and Thane. P.ocellatus forms a part of fishery along Mumbai and Ratnagiri coast (The Gazetteers Dept of Ratnagiri 1962 and Kolaba, 1964). Literature review revealed no study on food and feeding of P.ocellatus. The food and feeding habits will help in prediction of availability of fishes based on the availability of the food, prediction of migration with knowledge of decrease in preferred food, designing of suitable feeding strategy for maximum production.

\section{Materials and Methods}

Fish samples for the present study were collected from Malad, Vasai, Thane and Mahul creek every fortnight from June 2010 to September 2011. The samples were brought to the laboratory in ice-box. Morphological observation of features related to food and feeding habit was observed and noted and the fishes were cleaned and total length for each fish in millimetres and total weight in milligrams were recorded.

For understanding food and feeding habits following parameters were determined: 1) Relative gut length 2) Index of preponderance 3) Feeding intensity 4) Gastro somatic index.

\section{A. Relative gut length}

The value of Relative gut length was calculated by the formula:

$$
R G L=\frac{\text { Length of gut } \times 100}{\text { Total body length }}
$$

\section{B. General diet composition in terms of gut contents}

The gut contents were obtained by dissecting the stomach and microscopic examination of the contents was carried out. The food items were sorted out and identified up to the species level. The food items which could not be distinguished due to state of digestion were grouped as semi digested food.

\section{Index of preponderance (IoP)}

The occurrence method (Hynes 1950) was employed to express the percentage occurrence of each food item in the total number of stomachs examined. The percentage volume of each food item of major groups was estimated by displacement method (Pillay, 1952). The food items were graded by the method of index of preponderance (Natarajan and Jhingran, 
1961) which combines both frequency of occurrence and volumetric estimation by displacement method. It was resolved by the equation.

$$
I o P=\frac{V_{i} O_{i} \times 100}{\sum V_{i} O_{i}}
$$

Where,

IoP $=$ Index of preponderance of the food item.

$V_{i}=$ Percentage of volume index of the food item

$\mathrm{O}_{\mathrm{i}}=$ Percentage of occurrence index of the food item.

The IoP was determined separately for male, female and juvenile P.ocellatus

\section{Feeding intensity and feeding index}

The stomach fullness was visually examined and classified as gorged, full, three-fourth full, half full, one-fourth full, trace and empty depending on the fullness and amount of food contained in it.

$$
\text { Feeding Index }=\frac{X \times 100}{N \times \text { Points assigned }(10,8,6,4,2,1,0)}
$$

Where,

$\mathrm{X}=$ the number of particular type of fullness of stomach.

$\mathrm{N}=$ total number of stomachs examined.

\section{E. Gastrosomatic index (GaSI)}

GaSI was calculated using the method adopted by Desai (1970):

$$
\text { GaSI }=\frac{\text { weight of the stomach contents }}{\text { total weight of the fish }} \times 100
$$

\section{Results}

\section{A. Morphological features}

The following morphological features which are important for understanding food and feeding of P.ocellatus were observed.

Body elongated and cylindrical, dorsoventrally flattened head, protruding eyes for vision in dark and crescent shaped wide mouth extending below the eye orbit. A protruding lower jaw with many minute barbels for feeding on benthos. There were four rows of teeth on lower jaw with larger teeth in outer row and small villiform teeth in inner rows, the number of teeth decreased from outer to inner rows. Upper jaw too had four rows of teeth, the outer row having larger teeth with the front four teeth being the largest. The size decreased progressively on both the sides. The four teeth in the front were also slightly recurved. The inner teeth on the upper jaw were smaller in size. Ventral and dorsal pharyngeal tooth plates were observed in both jaws. There were four pairs of gill arch which are spaced apart and bear 16-18 tooth-like gill rakers on each. All the observed characters in terms of the position and the form of mouth and the dentition in jaws, all indicate that P.ocellatus is carnivorous.

Pelvic fins were united to form a sucking device which extended till the vent thus enabling the fish to adhere to the substratum in water and thereby maintain their position. A large wedge shaped caudal fin would facilitate acceleration in water. All these morphological features indicate that $P$ ocellatus seems to be carnivorous predatory fish.

\section{B. Relative gut length}

Relative gut length gives an idea of the nature of food. The range and average of relative gut length of P.ocellatus is as presented below:

Male $=0.51-0.85$ with an average of 0.68

Female $=0.55-0.88$ with an average of 0.70

Juvenile $=0.78-0.84$ with an average of 0.79

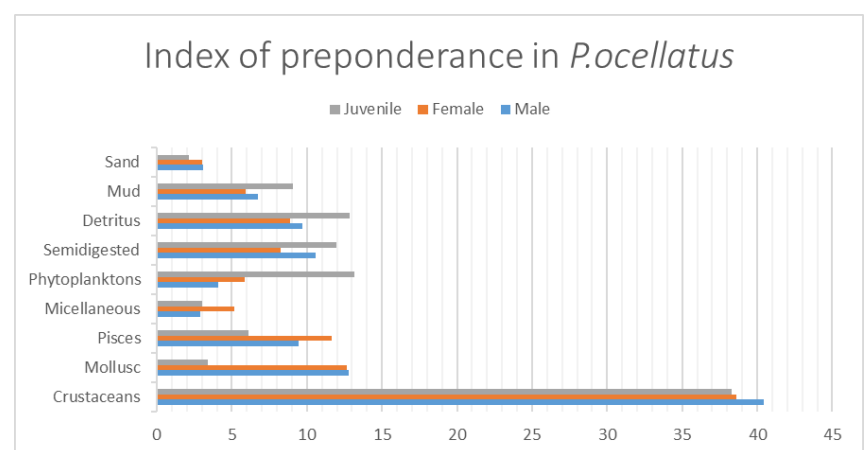

Fig. 1. Average Index of Preponderance of various food items in the gut of P.ocellatus

\section{General diet composition}

Average percentage of various food items in the P. ocellatus male, female and juvenile are presented in figure 1. Crustaceans formed the major bulk of the food with an average IoP value of $40.71 \%$ in male, $38.64 \%$ in female and $38.28 \%$ in juvenile. The food included zoea larvae of crab, zoea and megalopa of paenid and metapaenid prawns, mysis, acetes, lucifer, crustacean appendages, crustacean eggs and other whole and remanants of arthropods. Molluscans obtained in the food of P.ocellatus consisted of velliger of bivalve, clams, young ones of gastropods e.g Nassarius spp and Thiara spps, young ones of bivalves. Molluscans formed about $12.80 \%$ of the entire gut contents in male, $12.64 \%$ in female and $3.37 \%$ in juvenile P.ocellatus. The general diet composition also includes various adult and juvenile fishes e.g. Glossogobius guiris, Boleophthalmus dussumeiri, fish larvae, fish eggs, scales, fins etc. Of the general diet composition phytoplanktons observed in the gut contents of P.ocellatus consisted of Phylum Cyanophyta e.g Oscillatoria, Phylum Chlorophyta which included Spirogyra, Zygnema, Cladophora, Ulothrix and Phylum Bacillariophyta (Diatoms) which consisted of Melosira, Pleurosigma, Synedra, Nitzchia, Naviculla, and Pseudonitzchia.The general diet of P.ocellatus also consisted of miscellaneous food e.g nymphs of May fly, Hymenoptera larvae, Trichoptera larvae, polycheates worms e.g. nereis and glycera spp, Sagitta spp, rotiferons, dinoflagellates e.g. noctiluca, medusae and foraminiferans. Semi digested food in the gut content consisted of fishes, prawns, fish larvae in 
digested and semi digested state which could not be identified. The gut contents also revealed presence of detritus, mud and sand.

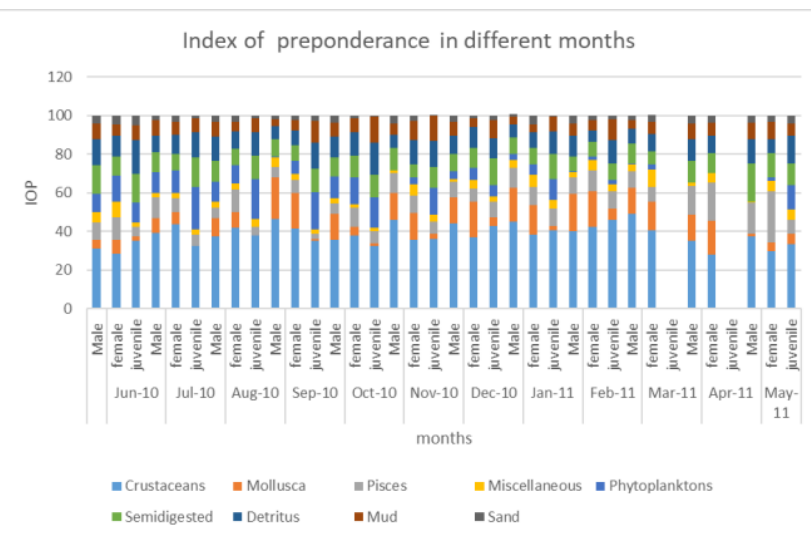

Fig. 2. Index of preponderance of various food items in the gut of male, female and juvenile P.ocellatus during different months

\section{Monthly variation in food composition}

Month wise index of preponderance of various food items in the guts of P.ocellatus is presented in figure 2 . Gut contents revealed that crustaceans formed the major bulk of food of males, females and juveniles in all seasons. Molluscs were the second most preferred food of males and females in all seasons. Pisces was the third most preferred food of male and female P.ocellatus during monsoon months from June to September and the post monsoon months from October to January. However, pisces formed the second most preferred food during the pre-monsoon months from February to May. Phytoplankton was observed in the guts of male, female and juvenile in monsoon and post monsoon period. However the contribution of planktons to the diet composition surmised from the gut content was very little during pre-monsoon months in male and female P.ocellatus. Miscellaneous food items like insects, annelids, cheatognaths, rotiferans dinoflagellates and cnidarians were recorded as per their availability in the creeks. Semi digested food, detritus, mud and sand were found throughout the period of study. Thus P.ocellatus was found to forage on a variety of food items in different seasons.
Percentage variations in feeding index in different months for male, female and juvenile P.ocellatus calculated in percentage are presented in tabular form in Table no. 3. The males are observed to be active feeders as reflected by feeding intensity in June 2010, January, February, May and June 2011 whereas the feeding activity was moderate in September and December 2010, January, March, April, July, August and September 2011 and the feeding intensity was poor in July, August, October and November 2010.

The data reveals that females fed actively in September 2010, May, June and September 2011 whereas the feeding intensity appears moderate in June, July, August 2010, January, February, April and July 2011 and females appear poor feeders in October, November, December 2010, March and August 2011.

Empty guts were observed in all months in male and female barring June 2010, July 2010 and October 2010 in male; October 2010 in female.

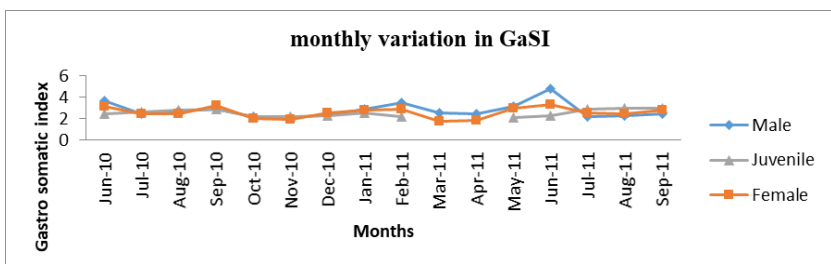

Fig. 3. Gastrosomatic index of P.ocellatus in different months

\section{E. Gastro somatic index (GaSI)}

The gastro somatic index of male and female P.ocellatus in different months is presented in Figure 3. In males Ga.S.I was found to be lowest in November 2010 (2.04) and highest in June 2011 (4.77). In females Ga.S.I was found to be lowest in March 2011 (1.71) and highest in June 2011(3.32). In juvenile the difference in value of Ga.S.I was comparatively less with values of 2.12 in May 2011 and 2.99 in September 2011.Juvenile fishes were not obtained in March 2011 and April 2011 months

\section{Discussion and Conclusion}

In fishes, both external (shape, size, position of mouth, shape of caudal fin) and internal morphology (stomach shape and size, gut length) provide important information on a species' feeding

Table 1

Feeding intensity in different months

\begin{tabular}{|l|l|l|l|l|l|l|l|l|l|}
\hline \multirow{2}{*}{ Months } & \multicolumn{4}{|c|}{ Poor feeding } & \multicolumn{3}{c|}{ Moderate feeding } & \multicolumn{3}{c|}{ Active feeding } \\
\cline { 2 - 11 } & Male & Female & Juvenile & Male & Female & Juvenile & Male & Female & Juvenile \\
\hline June 11 & 21.85 & 31.84 & 32.31 & 26.99 & 37.5 & 34.05 & 51.16 & 30.67 & 33.64 \\
\hline Jul 11 & 45.43 & 49.17 & 58 & 36.91 & 50.83 & 42 & 17.68 & 0 & 0 \\
\hline Aug 11 & 42.48 & 35.25 & 46.76 & 35.89 & 49.87 & 53.24 & 21.63 & 14.89 & 0 \\
\hline Sept 11 & 37.69 & 3.13 & 48.13 & 42.35 & 41.71 & 24.09 & 19.96 & 55.17 & 27.78 \\
\hline Oct 11 & 62.91 & 66.46 & 83.9 & 37.08 & 33.54 & 16.09 & 0 & 0 & 0 \\
\hline Nov 11 & 64.18 & 51.3 & 93.75 & 30.27 & 48.71 & 6.25 & 5.55 & 0 & 0 \\
\hline Dec 11 & 45.28 & 58.38 & 80.52 & 49.93 & 41.62 & 19.49 & 4.8 & 0 & 0 \\
\hline Jan 11 & 24 & 38.18 & 68.23 & 40.41 & 44.05 & 23.44 & 35.58 & 17.78 & 8.33 \\
\hline Feb 11 & 10.92 & 8.4 & 80 & 36.22 & 57.1 & 20 & 52.86 & 34.5 & 0 \\
\hline Mar 11 & 18.55 & 40.25 & NA & 51.37 & 35.95 & NA & 30.08 & 23.9 & NA \\
\hline Aprl 11 & 24.76 & 26.08 & NA & 52.5 & 30.33 & NA & 22.74 & 43.59 & NA \\
\hline May 11 & 10 & 0 & 91.67 & 31.67 & 32.17 & 8.33 & 58.33 & 67.83 & 0 \\
\hline
\end{tabular}


ecology (Keast and Webb, 1966; Hart, 1997; Wootton, 1998). For a given species of fish, the overall morphology is chiefly related to the nature of food, feeding habits, body size, shape and sex (Kapoor et al., 1975; Smith, 1989). P.ocellatus has an elongated and cylindrical body and dorsoventrally flattened head with protruding eyes for vision in dark. The fused pelvic fins form a sucking device which enables it to cling to rocks, stones and substratum in water. The large wedge shaped caudal fin of the fish may help for swift acceleration in water for capturing the prey and escaping from the predators. The mouth is wide and terminal with many pointed teeth well suited for carnivorous feeding. Moyle and Cech (1988) have observed that an elongate fusiform body, large terminal mouth, large caudal fin with anal and dorsal fins placed near it enable a swift attack on passing prey by the fishes. The characters of P.ocellatus mentioned above are in agreement with Moyle and Cech (1988).

P.ocellatus has a protruding lower jaw probably helping in benthic feeding. It has been reported by Alexander (1967) and Osse (1985) that the ability to protrude the jaw confers an advantage in specific circumstances such as obtaining benthic prey or food from otherwise inaccessible places. In P.ocellatus lower jaw is provided with minute barbels which may also help in benthic feeding. Barbels are sensory structures which carry tactile and chemical receptors and are used to locate prey. In P.ocellatus pharyngeal teeth are present in both dorsal and ventral jaw and the fish seems to be well adapted for mastication of food. Gasoline (1996) had opined that pharyngeal teeth are adapted to perform mastication.

Abuzinadah (1995) noticed that carnivorous fishes are characterized with few and limited number of gill rakers. Sebastian (2011) studied the gill rakers in Colletteichthys dussumieri which that they are short stubby and spaced apart, characteristics which according to author seems to prevent the escape of prey from the mouth of fish. The gill rakers in P.ocellatus too are short, stubby and spaced apart to prevent escape of prey as suggested by Sebastian (loc.cit.).

The stomach in P.ocellatus was observed to be highly muscular which is believed to be characteristic for carnivorous feeding as reported by Sebastian (loc.cit). The intestine in P.ocellatus was short and relatively straight. Carnivorous fishes normally have short and more or less straight intestine because the meat gets digested more easily (Pandey and Shukla, 2005; Serajuddin and Ali, 2005). P.ocellatus was observed to have a relatively short intestine with RGL having a range of 0.51-0.88 in adults and 0.78-0.84 in juveniles. Thus RGL which is less than 1 indicates that P.ocellatus is a carnivorous fish. It is generally accepted that RGL $<1$ indicates carnivorous diet, $1<\mathrm{RGL}<3$ indicates omnivorous diet and RGL $>3$ indicates herbivorous diet (Ward-Campbell et al 2005). Thus the morphological characters of $P$. ocellatus like shape of the body, shape of mouth, dentition, occurrence of pharyngeal teeth, muscular stomach, short and straight intestine, all the characters together confirm the carnivorous nature of the fish.
Most species of gobiidae are carnivorous (Coad, 2006). There are numerous studies reporting that most members of family gobiidae feed on benthic organisms such as molluscs, crustaceans and worms etc. (Simonoviv et al., 2001, Fitzsimous et al., 2006, Lederer et al., 2006). Geevarghese (1976) observed that Glossogobius guiris from Lake Veli in Kerala was carnivorous and fed on fishes and crustaceans whereas Marquez (1960) found $G$ guiris from Phillippines to be predominantly herbivorous. On the contrary Tandon (1962) found G.guiris from Varanasi (India) to be carnivorous feeding on fishes and insects. Many species of gobiids in the mudflats of coastal Mumbai like Beleophthalmus dentatus, B. boddaerti , B dussumieri were found to forage on phytoplanktons (Shettu,1993; Gore, 2007; Rathod and Patil, 2009). The adult P.ocellatus was found to feed on crustaceans, molluscs, fishes, miscellaneous groups of organisms and phytoplanktons. Thus P.ocellatus can be said to be predominantly carnivorous, though phytoplankton was comparatively predominant in gut contents of juveniles.

Based on the extent of variation in the selection of food, Nikolsky (1963) classified fishes as (a) euryphagic: feeding on a variety of food (b) stenophagic: feeding on few selected types of food and (c) monophagic: feeding only on a single type of food. P.ocellatus has a wide variety of organism mainly animals in the gut content and it can be presumed that the fish is a euryphagus feeder as it feeds on wide variety of food like crustaceans, copepods, smaller invertebrates, molluscs, fishes and small quantity of algae and diatoms. The semi digested food containing fish larvae, mollusc, prawns etc were found in large quantity often in a state in which it was difficult to identify. Barring a few months, the guts were found to be empty in male, female and juvenile P.ocellatus. According to Lawson and Ajibola (2010) the occurrence of empty guts is a characteristic feature of predatory fishes which is associated with rapid rate of digestion. The empty guts of P.ocellatus thus seem to indicate predatory mode of feeding in P.ocellatus. The presence of detritus, mud and sand in the gut contents of male, female and juvenile P.ocellatus collectively indicate benthic feeding.

The material food of fishes was classified by Schaperclaus (1933) into 3 groups' i.e. main food, occasional food and emergency food. Nikolsky (1963) classified the food of fishes based on feeding habits into 4 groups' i.e. basic food, secondary food, incidental food and obligatory food. The most preferred food of P.ocellatus throughout the year was crustaceans. Mollusc ranked second followed by Pisces and detritus. Phytoplankton was also recorded from the guts of male, female and juveniles but juveniles were found to prefer phytoplanktons in contrast to adults. Miscellanous food items like insects, rotiferans, foraminiferans, cnidarians, medusae, annelids and chaetognaths were often found in the gut contents of P.ocellatus though in smaller proportions. Detritus was found in the gut contents of male, female and juvenile P.ocellatus in considerable amount. Thus it can be concluded that in adult P.ocellatus, crustaceans formed the basic food while mollusc 
and Pisces formed the secondary food. Detritus formed the obligatory content and phytoplankton and miscellaneous food items were incidental food. Seasonal variations are observed in gut contents of P.ocellatus especially in the different types of crustaceans in the diet depending on their availability, though crustaceans formed predominant food in P.ocellatus.

Kader et al (1988a) concluded on the basis of the analysis of the stomach contents of Gobioides rubicundus that it was mainly carnivorous and even cannibalistic at times in its feeding habits. Rao and Rao (2002) reported that in Glossogobius guiris from Gosthani estuary cannibalism was noticed during peak spawning season due to abundant availability of fry of its own species. In P.ocellatus though cannibalism could be observed its occurrence was not regular in the general diet.

The food and feeding intensity of the fishes vary from month to month due to the changes in the composition of food occurring at different seasons of the year (Bhuiyan et al., 1997, 1998, 1999). In the gut contents thus crustaceans consisted of crab larvae, prawn larvae and at times large paenid prawns. P.ocellatus was also found to feed on mysis, acetes, lucifer, eggs and appendages of crustaceans. The second most prefered food in P.ocellatus consists of Mollusc e.g bivalves, gastropods, velliger, clams and slug. Pisces were the next preferred food of P.ocellatus with its IoP exhibiting a sharp increase in pre monsoon months from February to May. The fish was found to swallow large preys like fish, fish larvae and prawns. The fish was found to exhibit cannibalism since the gut contents also revealed presence of adult P.ocellatus ingested as food. P.ocellatus can thus be said to be hyperphagic and cannibalistic.

The P.ocellatus was found to show seasonal variation in food. The intake of variety of food depends on the availability and the preference of the fish to feed on a particular type of food. The ultimate objective of dietary changes is to maximize the energy intake, enhance growth rate and minimize the risk of predation in competing for food with bigger predators (Bradstreet and Brown 1985). The P.ocellatus was found to forage on a variety of food items in different season. However, there seems to be definite niche segregation between adults and juveniles in terms of preferred food especially related to the seasons during the period of study.

In terms of feeding intensity, the fish can be categorised as active feeders, moderate feeders and poor feeders. Data on feeding intensity revealed male P.ocellatus to be actively fed than females. The percentage of emptiness and stomach fullness indices are very important to assess feeding intensity (Shanti Prabha and Manjunalatha, 2008). Feeding intensity is negatively related to the percentage of empty stomachs (Bowman and Bowman, 1980).

The males exhibited high feeding intensity in June, February 2010, May and June 2011 Females were actively fed in September 2010, May, June and September 2011. The high feeding in males occurred during peak spawning and also after immediately spawning while in female high feeding intensity was observed after spawning probably to recover the spent stage. Moderate feeding was observed in males in September, December 2010, January, March, April, July, August and September 2011 while in female it was from June- August 2010, January, February, April and June 2011. Poor feeding was observed in July, August, October and November 2010 in males and October, November, December 2010, March and August 2011 in females. The poor feeding of November 2010 in male and November December 2010 in female coincides with the resting period in P.ocellatus.

The feeding intensity of a fish is related to its stage of maturity, reproductive state and availability of food items in its environment (Maddock and Burton, 1999; Kiran and Puttaiah, 2004). The occurrence of poor feeding coincide with peak breeding in other fishes has been reported by Serajuddin $\mathrm{et} \mathrm{al}$. (1998), Bhuiyan et al. (2006).

The gastro somatic index in male and female was found to be highest during June 2010 and 2011 which agrees well with the feeding intensity.

In conclusion P.ocellatus from the coast of Mumbai was found to be carnivorous, euryphagus and predatory fish. It also fed on phytoplankton. It also at times showed cannibalism although it was not a common occurrence observed but only in summer when food was scarce. It was found to be detritus feeder, feeding on the benthos and among complex network of mangrove roots. P.ocellatus can also be classified as hyperphagic fish consuming large sized prey. Thus they occupy the position of secondary and tertiary consumers in the food chain determined by the size and type of the food consumed by the fish. The diet composition of the fish was mainly crustaceans, molluscs, Pisces, phytoplankton and traces of other food items which varied as per their availability. An analysis of seasonal variation in food preference, and feeding intensity reveal that the male and female P.ocellatus had the same preference throughout the seasons which was different for the juvenile. In this case preference seems to be function of the size/maturity of the fish rather than the sex, niche segregation in terms of preferred food could probably be a strategy for ensuring survival and growth of the juvenile P.ocellatus.

\section{References}

[1] Abuzinadah, O. A. (1995), Gill raker morphology in some red sea fishes of different feeding preferences, JKAU: Mar. Sci., vol. 6, pp. 93-122.

[2] Alexander, R.M.N. (1967), Functional design in fishes, Hutchinson University Library, London, pp. 160.

[3] Bhuiyan, A.S., Begum, M. and Nessa, Q. (1997), Observation of the food and feeding habit of Clupisoma atherinoides (Bloch) (Siluriformes: Schilbidae), Univ. J. Zool., Rajshahi.Univ, 16: 1-5.

[4] Bhuiyan, A.S., Nessa, Q. and Begum, M. (1998), The food and feeding habit of Puntius gonionotus (Bleeker) (Cyprinidae: Cypriniformes) Bangladesh, J. Zool, 26 (1): 73-78.

[5] Bhuiyan, A.S., Nessa, Q. and Hossain, M.D. (1999), Seasonal pattern of feeding of grey mullet, Mugil cephalus (L) (Mugiliformes: Mugilidae), Pakistan. J. Zool., 31(1): 295-297.

[6] Bhuiyan, A.S., Afroz, S. and Zaman, T. (2006), Food and feeding habit of the juvenile and adult snake head, Channa punctatus (Bloch), J. Life Earth. Sci. 1(2): 53-54. 
[7] Bowman, R. E. and Bowman, E. W. (1980), Diurnal variation in the feeding intensity and catchability of silver hake (Merluccius bilinearis). Can. J. Fish. Aquat. Sci., 37: 1565-1572.

[8] Bradstreet, M.S.W. and Brown, R.G.B. (1985), Feeding ecology of the Atlantic Alcidae pp 263-318 In Nettleship D.N\& Birkhead, T.R (eds). The Atlantic Alcidae, Academic Press.

[9] Coad, B.W. (2006), The freshwater fishes of Iran, Family Gobiidae, Genus Neogobius www.briancoad.com.

[10] Day, F 1873, On new and imperfectly known fishes of India. Proceedings of the Zoological Society of London (pt I): 236-240.

[11] Desai, V. R., 1970, Studies on the fishery and biology of Tor tot (Ham) from river Narbada, J. Indian.Fish.Soc., 2: 101-112.

[12] Fitzsomons, J., Williston, B., Williston, G., Bravener, G., Jonas, J.L., Claramunt, R.M., Marsden, J.E. and Ellrott, B.J. (2006), Laboratory estimates of Salmonine Egg predation by round gobies (Neogobius melanostomus), Sculpins (Cottus cognatus and C.bairdi) and ceay fish(Orconectes propinquus), Journal of Great Lakes Research, 32(2): 227-241.

[13] Gosline, W.A. (1996), Structures associated with feeding in three broad mouthed benthic fish groups, Environ. Biol. Fish., 47(4): 399-405.

[14] Hart, P.J.B. (1997), Foraging tactics pp 104-113, In: Godin J.G.J (ed) Behavioural ecology of teleost fishes, oxford University Press, New York.

[15] Hynes, H.B.N. (1950), The food of the freshwater sticklebacks (Gastrosteus aculeatus and Pygosteus pungitius) with a review of methods used in studies of the food of fishes, J. Anim. Ecol, 19: 36-58.

[16] Kader, M. A, Bhuiyan, A.L. and Manzur-I-Khuda, A.R.M.M. (1988a), Food and feeding habits of Gobioides rubicundus and some feeding experiments on it, Indian. J. Fish., 35(4): 312-316.

[17] Kapoor, B.J., Smith, H. and Verighina, I. A. (1975), The alimentary canal and digestion in teleosts, In: Advances in marine biology (F.S. Russell and M. younge eds.) London. Academic Press, pp. 109-239.

[18] Keast, A. and Webb, D. (1966), Mouth and body form relative to feeding ecology in the fish fauna of a small lake, Lake Opinicon, Ontario, Journal of Fishes Research Board of Canada., 23 (12): 1845-1874.

[19] Kiran, B.R. and E.T. Puttaiah, 2004. Food and feeding habits of Salmostoma untrahi from Bhadra Reservoir, Karnataka. Indian J. Fish. 51(3):335-344.

[20] Lawson, E.O. and Ajibola, E.T. (2010), Food and feeding habits and reproduction in Frillfin goby, Bathygobius soporator (Cuvier and Valenciennes, 1837) in the Badagry creek, Lagos, Nigeria, International Journal of Biodiversity and Conservation, 2(12): 414-412.

[21] Maddock, D.M. and Burton, M.P.M. (1999), Gross and Histological observations of ovarian development and related condition changes in American plaice, J.Fish.Biol., 53: 928-944

[22] Lederer, A., Massart, J. and Janssen, J. 2006, Impact of round gobies (Neogobius melanostomus) on dreissenids (Dreissena polymorpha and Dreissena bugensis) and the associated macro invertebrate community across in invasion front, Journal of Great Lakes Research, 32(1):1-10.

[23] Gore, B.M. (2007), Biometry of mudskipper Boleophthalmus boddarti, $\mathrm{Ph} . \mathrm{D}$. Thesis, University of Mumbai.

[24] Geevarghese, C. (1976), Studies on some aspects of the biology of Glossogobius giuris (Ham) with a taxonomic note on six gobioid fishes occurring in and around Trivandrum M. Phil Dissertation, Department of Aquatic Biology and Fisheries, Kerala University, pp. 90.

[25] Marquez, J.R.S. (1960), Age and size at sexual maturity of white goby (Glossogobius giuris) a common species of fish of Laguna de Bay, with notes on its food habits, Phillippines Journal of Fisheries, 8(1): 71-101.

[26] Moyle, P.B. and Cech Jr, J.J. (1988), Fishes: An Introduction to Ichthyology, 2nd ed. Prentice-Hall, Inc, Englewood Cliffs, New Jersey, pp. 593.
[27] Mutsaddi, K.B. and Bal D.V. (1973), Gobies from the intertidal region of Bombay, Indian J. Fish, 20, pp475-486

[28] Nataranjan, A. V and Jhingran, V.G.1961, 'Index of preponderance: a method of grading the food elements in the stomach analysis of fishes', Indian J. Fish., 8:54-59.

[29] Nikolsky, G.V. (1963), The ecology of fishes, Academic press New York, pp 362.

[30] Osse, J.W.M. (1985), Jaw protrusion, an optimization of the feeding apparatus of teleosts? Acta Biotheoritica, 34: 219-232.

[31] Pandey, K. and Shukla, J.P. (2005), Fish and Fisheries, Rastogi publications, Meerut, pp. 504.

[32] Pillay, T.V.R. (1952), A critique of the methods of study of food of fishes, J.Zool.Soc. India, 4: 185-200.

[33] Rao, L.M. and Rao, S.P. (2002), Food and feeding habits of Glossogobius guiris from Gosthani estuary, Inland. J. Fish, vol. 49, no. 1, pp. 35-40.

[34] Rathod, S.D. (2005), Effect of pollution on mudskipper fishery of Ulhas river Estuary with a special reference to the biology of Boleophthalmus dussumieri (Cuv\& Val). A minor project, Univ of Mumbai.

[35] Schaperclause, W. (1933) US Department of Interior, Fish Wildl. Serv. Fish leafl.No. 31, pp. 261.

[36] Sebastian, R. (2011), Biology of flat Toad fish, Coletteichthys dussumieri (Valenciennes, 1837) of Cochin Estuary, Ph.D. Thesis, Cochin University of Science and Technology.

[37] Serajuddin, M., Khan, A.A. and Mustafa, S. (1998), Food and Feeding habits of the spiny eel, Masta cembelus armatus, Asian Fish Sci, 11: 271278.

[38] Serajuddin, M. and Ali, R. (2005), Food and feeding habits of striped spiny eel, Macrognathus pancalus (Hamilton), Indian. J. Fish, 52 (1): 8186.

[39] Shanti Prabha, Y. and Manjulatha, C. (2008), Food and Feeding habits of Upeneus vittatus (Forskal, 1775) from Vishakhapatnam coast (Andhra Pradesh) of India, International Journal of Zoological Research, 4: 59-63.

[40] Skazkina, Y.P. and Kostyuchenko, V.A. (1968), Food consumption of the Azov goby Neogobius melanostomus(Pallas), Probl Ichthyol, 8:238-245.

[41] Simonovic, P. Paunovic, M. and Popovics, S. (2001), Morphology, feeding and reproduction of the round goby Neogobius melanostomus(Pallas) in the Danube river basin, Yugoslavia, J. Great Lakes Res, 27(3): 281-289.

[42] Shettu, N. (1993), Studies on certain aspects of biology of the gobid fish Boleophthalmus dentatus (Cuv. \& Val.), Ph.D. Thesis, CIFE.

[43] Smith, L.S. (1989), Digestive functions in teleost fish. In fish nutrition (J.E Halvert, ed.) San Diego: Academic Press, pp.331-421.

[44] Tandon, K. K. (1962), Biology of Channa punctatus(Bloch) and Glossogobius giuris (Ham.), Research Bulletin. Punjab University, New Series: Science 13:263-268.

[45] Ward-Campbell, B.M.S., Beamish, F.W.H. and Kongchaiya, C. (2005), Morphological characteristics in relation to diet in five coexisting Thai fish species, Journal of Fish Biology, 67:1266-1279.

[46] Weatherley, A.H. (1972), Growth and Ecology of Fish Population, Academic Press, London.

[47] Wootton, R.J. (1998), Ecology of teleost fishes, 2nd edn, Fish and Fisheris Sereis no.24. Kluwer Academic Publishers, London.

[48] Maharashtra State Gazetteers Ratnagiri district 1962, Revised edition of Vol. X of original Gazetteer of the Bombay Presidency relating to Ratnagiri and Sawantwadi,

http://www.maharashra.gov.in/english/gazetteer/RATNAGIRI/preface html, 23/03/2010 